\title{
NOTAS PARA A HISTÓRIA DAS INSTITUIÇÕES ESCOLARES: "RELATÓRIO SOBRE A MARCHA E ESTADO DA ESCOLA PRIMÁRIA NEUTRALIDADE DURANTE O ANO DE 1884"
}

\author{
Analete Regina Schelbauer \\ arschelbauer@uem.br \\ Universidade Estadual de Maringá - UEM
}

O documento, objeto desta apresentação, é o "Relatório sobre a marcha e estado da Escola Primária Neutralidade durante o ano de 1884", apresentado pelo diretor João Köpke e co-diretor Antonio da Silva Jardim, e encaminhado ao Inspetor Geral da Instrução Pública da Província de São Paulo, Antonio Carlos Ribeiro de Andrade Machado e Silva, em 12 de maio de 1885.

A fonte em questão fez parte do corpus documental da pesquisa de doutorado desenvolvida no Programa de Pós-Graduação em Educação da Universidade de São Paulo, a qual resultou na tese intitulada "O método de ensino intuitivo na província de São Paulo (1870-1889)" (SCHELBAUER, 2003). Parte da documentação manuscrita do Arquivo do Estado de São Paulo, o Relatório encontra-se catalogado na Série Instrução Pública sob o número de ordem 5010, lata 1. Instrução Pública. Ensino Particular. Ofícios sem localidade (1862-1888).

A Escola Primária Neutralidade foi objeto de estudo pontual em capítulo publicado anteriormente (SCHELBAUER, 2009), no qual se examinou aspectos acerca da história da instituição, seus personagens e suas práticas escolares, com o intuito de compreender o movimento de criação de escolas de ensino elementar por intelectuais que estiveram envolvidos com o movimento republicano, na província de São Paulo, em fins do século XIX. Buscou-se situar a instituição em questão como uma experiência de caráter inovador, vinculada a iniciativa de particulares, e evidenciar o empenho de seus educadores na propagação de modernos preceitos pedagógicos que estavam em circulação na época, dentre eles, o ensino pelo método intuitivo.

A instituição, seus personagens e suas práticas também estiveram contemplados nos trabalhos de Hilsdorf (1977 e 1986) intitulados, respectivamente, "Escolas americanas de confissão protestante na província de São Paulo: um estudo de suas origens" e "Francisco Rangel Pestana: jornalista, político, educador"; bem como na tese de Panizzolo (2006) "João Köpke e a Escola Republicana: criador de leituras, escritor da modernidade". Organizado por Fávero e Britto (2002) "O dicionário de educadores no Brasil" apresenta, em um de seus verbetes, a trajetória do diretor da Escola - João Köpke (MORTATTI, 2002).

O Relatório, precedido de ofício e do Programa das Conferências Pedagógicas, faz parte das práticas instituídas pelo Regulamento Provincial de 18 de abril de 1869. No ofício manuscrito constam informações sobre a Escola Primária Neutralidade - aula masculina - quanto ao seu programa de ensino, "línguas e ciências no desenvolvimento compatível com a potência mental no período dos 7 aos 14 anos, idade mínima e máxima de admissão". Informa a frequência de 53 alunos matriculados no ano de 1885, sendo 5 gratuitos, traz a Relação dos alunos matriculados, com os nomes, a filiação e a residência dos pais. Afirma o caráter laico da instituição "na direção moral dos alunos não se preocupa com as confissões religiosas, políticas ou filosóficas para que a família tenha, por 
ventura, preferência", e indica o encaminhamento do Relatório do ano de 1884. Junto ao Ofício e ao Relatório, encaminha a "Programação das Conferências Pedagógicas" que se realizariam, as quintas-feiras, nas instalações da escola (OFÍCIO, 12/05/1885).

O "Programa das Conferências Pedagógicas do Ano de 1885" é um documento impresso, precedido dos seguintes dizeres:

Realizam-se às quintas-feiras, no salão de conferências desta instituição, as 7:30 da tarde, as conferências semanais, públicas e gratuitas, sobre ensino, sendo preletores os anunciados nos jornais do dia, sobre as teses do programa anual anexo: e, para elas, é com sua Exma. Família especialmente convidado. Rua da Conceição, n 42 e 44. (PROGRAMMA, 1885).

Dentre os temas propostos, a educação aparece como objeto de estudo em seus diversos aspectos, ora discute as questões dos métodos de ensino, seus teóricos e suas práticas, ora a formação de professores, a importância do conhecimento psicológico para essa formação, o papel das escolas normais, as relações entre família e escola, as questões relacionadas à educação moral, física e intelectual. Temas que objetivavam dar publicidade as idéias dos educadores de vanguarda que estavam à frente da instituição. Tais conferências foram amplamente noticiadas pelo jornal republicano A Província de São Paulo, durante os anos de 1884 e 1885 (SCHELBAUER, 2003; 2009).

Publicado pela Leroy King Bookwater Typographia do King, São Paulo, 1885, o Relatório possui 21 páginas impressas, distribuídas entre o texto e os anexos. Inicialmente, o documento faz uma alusão ao plano de educação da escola, que findara seu primeiro ano de funcionamento em 1884, objetivando narrar os esforços empreendidos e corroborados "pelos princípios de franqueza, auxílio e fiscalização que devem existir entre a Família e a Escola, entrelaçadas no nobílimo fím da elevação física, mental e moral da criança" (RELATORIO, 1885).

Dividido em treze partes, a primeira é dedicada a apresentar seus diretores e idealizadores, inicialmente João Köpke, diretor da Escola Primaria Neutralidade:

Formado em Ciências Jurídicas e Sociais pela nossa Faculdade, em 1875, o Bacharel João Köpke, após diversas tentativas na magistratura, para seguir a carreira em cuja aspirância tanto tempo gastara, deliberou abraçar a profissão de seu Pai, o fundador do Colégio Köpke, em Petrópolis, a qual em épocas acadêmicas exercera por necessidade e gosto. Dedicado ao magistério particular nesta cidade e na de Campinas, afinal pediu aos poderes mais segura subsistência, obtendo, por concurso, a cadeira de Geografia e História do Curso Anexo a Faculdade de Direito; mas não esquecido de sua melhor tendência, o ensino primário, a idéia veio-lhe da criação de uma escola em que fosse esse ministrado sem inutilidades, nem as deficiências do atual e do suposto ensino secundário (RELATORIO, 1885, p. 3-4). 
Na sequência, Antonio Silva Jardim, seu co-diretor:

Também em 1882 formado pela nossa Faculdade, após uma leve tentativa jurídica, o Bacharel A. da Silva Jardim, relembrado de seus antecedentes de Família e escolares, pensou continuar a exercer o magistério, tendo antes alcançado, por concurso, após exercer de 1880 a 1883, a cadeira do Curso Anexo a Escola Normal, a $1^{\mathrm{a}}$. cadeira do Curso desse estabelecimento (Gramática e Língua Nacional) (RELATORIO, 1885, p. 4).

E, por fim, é apresentado Arthur Gomes, auxiliar nas atividades de direção da Escola: "Estudante do $2^{\circ}$. Ano da Faculdade, professor particular na Capital, e ex-diretor de uma escola em Sorocaba, era o Senhor Arthur Gomes, mais tarde nomeado interinamente Professor de Frances da citada Escola Normal" (RELATORIO, 1885, p. 4).

O segundo item fixa as bases da nova instituição, sendo elas de ordem moral, intelectual e material:

Morais seriam as de um ensino dito leigo, não negativo ou voltairiano, nem sectário, e sim em que desenvolvessem-se os bons sentimentos da infância, por processos estéticos e intelectuais, além do exemplo, sem a especialidade, porém, de um culto qualquer, pela dificuldade e grandeza da tarefa, melhormente confiada às Mães. (...) Intelectuais seriam as de um ensino primário, de 2 graus, correspondendo aproximadamente a $2^{\mathrm{a}}$ infância (7-14 anos); ensinada a Língua Materna (fala e escrita), o Cálculo, o Canto e o Desenho; - as línguas estranhas; neo-latinas, o Francês, o Italiano e o Espanhol; - e o Inglês; - as Ciências relativas ao mundo bruto, ao animado e ao social na sua parte a mais concreta (RELATORIO, 1885, p. 4).

Ainda sobre as bases intelectuais, o Relatório enfatiza que o ensino na nova escola resumir-se-á a "poucos professores e bastante trabalho; poucos livros e muita atenção; rara decoração, muitas notas e exercícios” (RELATORIO, 1885, p. 5).

Quanto às bases materiais, descreve a casa na qual funciona a Escola situada na Rua da Conceição, n. 44, e alguns aparelhos trazidos por Köpke de Campinas, além da mobília provisória, listada no anexo de número 3.

O terceiro item é dedicado a relatar sobre o início dos trabalhos no ano de 1884, a distribuição das matérias de ensino entre os três professores anteriormente citados, os quais foram "coadjuvados no ensino das turmas menores por uma jovem senhora". E, a publicação de Livros de Leitura de autoria de João Köpke, intitulados "Lições instrutivas $e$ morais, para o uso das classes" (RELATORIO, 1885, p. 5).

A marcha da Escola desde a sua abertura é objeto do item IV do Relatório. Mereceu destaque as modificações da casa para adequá-la as necessidades do ensino. Seus diretores apresentam como resultado das modificações, a formação de uma sala principal e de uma "sala para pequena aula", a preparação de um Gabinete de Física e armários apropriados, o 
aumento da área destinada ao local de recreio, a condução de gás para a casa, a instituição de aulas ao ar livre, a aquisição de um piano para as aulas de canto coral. Este item contempla, também, a ata da reunião de 25 de junho de 1884, na qual os professores deliberaram sobre o funcionamento da Escola (RELATORIO, 1885, p. 6).

$\mathrm{O}$ ingresso de novos professores é relatado no item número $\mathrm{V}$, no qual constam os nomes de A. Caetano de Campos para ministrar o ensino de química e física, de G. Giraudon e Roso Lagoa, para as aulas de canto e desenho, respectivamente. Neste mesmo item, informam sobre a mudança de horário da escola que passou a funcionar das 10 as 3 da tarde, com intervalo para recreio de 10 minutos (RELATORIO, 1885).

As conferências didáticas são objeto de apresentação no item VI do Relatório. Inauguradas no dia 14 de setembro de 1884, com um discurso do diretor da Escola, teve sequência, naquele ano, com os seguintes temas: "Educação em geral, sua evolução histórica até os nossos dias: seu ideal; sua tríplice divisão; e especialmente da educação intelectual na escola primária", as "Relações entre a Família e a Escola" e "O Ensino Primário", proferidas por Antonio Silva Jardim. O tema da "Educação estética" foi abordado por João Köpke. O processo para a aprendizagem das "Línguas em geral" foi tratado pelo professor Arthur Gomes, o qual recomendou o ensino pela Cartilha Maternal de J. de Deus (RELATORIO, 1885, p. 8-9).

A temática do ensino da língua materna foi retomada por João Köpke e Silva Jardim para além das conferências previstas no Regulamento da Escola. Jardim, a convite da Sociedade Auxiliadora da Instrução, realizou mais três conferências sobre métodos de leitura, em geral, sobre o Método João de Deus e sobre a Reforma do ensino da língua materna, conforme consta no Relatório de $1885^{\mathrm{i}}$.

Ao tornar públicas as ideias educacionais defendidas por seus mentores e o trabalho desenvolvido pela Instituição, as conferências gratuitas, anunciadas e noticiadas pelos jornais da cidade, objetivavam proporcionar aos professores e ao público em geral, o debate e a formação acerca de temas relacionados à educação.

O item VII comunica a influência exercida pela escola sobre algumas províncias, finalidade que havia sido alcançada naquele ano com a elaboração do Programa para a Instrução Primária da Província do Paraná, a convite do Presidente Brazilio Augusto Machado de Oliveira e elaborado pela Congregação da Escola Primária Neutralidade.

Neste mesmo item, Kopke e Jardim dirigem-se ao Presidente da Província de São Paulo, para reiterar a necessidade de nomeação, de professores formados na escola Normal, nas cadeiras públicas da capital e das importantes cidades da província (RELATÓRIO, 1885).

O item VIII refere-se ao Regulamento de funcionamento da instituição. O item IX versa sobre as festas escolares, familiares e cívicas, institui as datas comemorativas e festivas, além de mencionar a prática do envio dos boletins escolares como forma de acompanhamento da marcha intelectual do aluno, pelas famílias. Os três próximos itens (X, XI e XII) versam sobre os exames escolares anuais os quais foram realizados, naquele ano, nos dias 26, 27 e 28 de novembro. A prática dos exames é descrita com minúcia, anuncia desde os 150 convites distribuídos entre os familiares dos alunos e autoridades escolares, até o programa dos exames, a comissão examinadora e suas respectivas matérias, a cerimônia de abertura dos exames e as características das provas, sendo em sua maioria orais, como também escritas "como convém ao ensino primário" (RELATORIO, 1885, p. 15). 
O último item faz algumas considerações sobre as realizações da Escola no ensino primário e reitera seu caráter laico e sua intencionalidade em desenvolver funções mentais e morais e não apenas "adornar a memória" (RELATORIO, 1885, p. 17).

Nos anexos estão contemplados os seguintes itens:

- Anexo n. 1 - Corpo Docente;

- Anexo n. 2 - Corpo Discente;

- Anexo n. 3 - Material de Ensino;

- Anexo n. 4 - Programa dos Primeiros Exames Anuais;

- Anexo n. 5 - Receita e despesa da escola, no decurso de 1 de Março a 31 de Dezembro de 1884.

Constam do corpo docente, os professores: João Köpke; Antonio Silva Jardim; Arthur Gomes; Roso Lagoa; Gabriel Giraudon; Antonio Caetano de Campos. Do corpo discente, 35 alunos matriculados e 4 com matrículas canceladas ou infreqüentes no ano de 1884 .

Dentre os materiais de ensino estão listados os do Gabinete de Física, que contemplam aparelhos e objetos para o ensino de noções gerais, barologia, termologia, acústica, óptica, magnetismo, eletricidade, além de alguns aparelhos avulsos. Também estão relacionados materiais para o ensino da matemática, astronomia, geografia, geologia e meteorologia, anatomia, zoologia, botânica e mineralogia, mecânica, técnica mecânica e química, construção cívica, mineração, economia domestica e agronômica, estratégia militar e marinha, escultura, pintura e arquitetura, história, etnografia, línguas, noções gerais. Além da mobília existente e da mobília provisória.

Destes materiais destacam-se o Museu escolar do Dr. Saffray, os Álbuns de gravuras para o ensino das noções gerais, os Quadros zoológicos de Mme. Pape-Carpantier para o ensino da zoologia, o Boulier de Mme. Pape-Carpantier, a Coleção de sólidos para o ensino da matemática, além dos quadros geográficos, mapas, globos e pranchas brockaus, artefatos que figurariam nas práticas escolares relacionadas ao método de ensino intuitivo, método que teve em João Köpke um de seus preconizadores e divulgadores no Brasil.

Além dos materiais voltados a prática do ensino intuitivo, do caráter laico da instituição, a mesma traz enquanto inovação os exames escolares e as festas didáticas práticas que configurariam a rotina das escolas públicas após a implantação da república nas escolas públicas.

Ao deter o olhar sobre os documentos impressos e manuscritos voltados a descrição da rotina das escolas primárias, públicas e particulares, da província de São Paulo, o leitor poderá vislumbrar aspectos significativos das práticas escolares, dos educadores, das ideias educacionais, dos alunos que compuseram os momentos iniciais de configuração de nossa escola primária. Que essa fonte documental, aqui apresentada, possa contribuir para a pesquisa e a escrita da história das instituições escolares e da escolarização primária no Brasil em fins dos oitocentos. 


\section{FONTES}

RELATÓRIO sobre a marcha e estado da Escola Primária Neutralidade durante o ano de 1884. Série Instrução Pública sob o número de ordem 5010, lata 1. Instrução Pública. Ensino Particular. Ofícios sem localidade (1862-1888).

OFÍCIO encaminhado pelo Diretor da Escola Primária Neutralidade - Dr. João Köpke ao Ilmo Sr. Dr. Antonio Carlos Ribeiro de Andrade Machado e Silva, Inspetor Geral da Instrução Pública da Província de São Paulo, em 12 de maio de 1885. Série Instrução Pública sob o número de ordem 5010, lata 1. Instrução Pública. Ensino Particular. Ofícios sem localidade (1862-1888).

PROGRAMA das Conferências Pedagógicas. Escola Primária Neutralidade. 1885. Série Instrução Pública sob o número de ordem 5010, lata 1. Instrução Pública. Ensino Particular. Ofícios sem localidade (1862-1888).

\section{REFERÊNCIAS:}

FÁVERO, Maria de Lourdes de Albuquerque e BRITTO, Jader de Medeiros (orgs.). Dicionário de educadores no Brasil. $2^{\mathrm{a}}$. Ed. Rio de Janeiro: Editora UFRJ / MEC-InepComped, 2002.

HILSDORF (BARBANTI) Maria L. S. Escolas americanas de confissão protestante na província de São Paulo: um estudo de suas origens. 1977. Dissertação (Mestrado) Faculdade de Educação, Universidade de São Paulo. São Paulo, 1977.

HILSDORF, Maria Lucia Spedo. Francisco Rangel Pestana: jornalista, político, educador. 1986. Tese (Doutorado) - Faculdade de Educação, Universidade de São Paulo. São Paulo, 1986.

MORTATTI, Maria do Rosário Longo. João Köpke. In: FÁVERO, Maria de Lourdes de Albuquerque e BRITTO, Jader de Medeiros (orgs.). Dicionário de educadores no Brasil. $2^{\mathrm{a}}$. Ed. Rio de Janeiro: Editora UFRJ / MEC-Inep-Comped, 2002, pp. 546-554.

MORTATTI, Maria do Rosário Longo. Os sentidos da alfabetização. São Paulo 18761994. São Paulo: Editora da UNESP; CONPED, 2000.

SCHELBAUER, Analete Regina. A constituição do método de ensino intuitivo na província de São Paulo (1870-1889). 2003. Tese (Doutorado) - Faculdade de Educação, Universidade de São Paulo. São Paulo, 2003.

SCHELBAUER, Analete Regina. Escola Primária Neutralidade: personagens e práticas escolares. In: MARTINS, Ângela Maria Souza, BONATO, Nailda Marinho da Costa (orgs.). Trajetórias históricas da educação. Rio de Janeiro: Rovelle, 2009, pp. 19-40.

PANIZZOLO, Claudia. João Köpke e a Escola Republicana: criador de leituras, escritor da modernidade. 2006. Tese (Doutorado em Educação) - Pontifícia Universidade Católica de São Paulo. São Paulo, 2006.

\footnotetext{
${ }^{\mathrm{i}}$ Sobre as conferências proferidas por Jardim e Köpke ver: Schelbauer (2003, 2009) e Mortatti (2000).
} 